\title{
Nano-Mechanical Properties and Creep Behavior of Ti6A14V Fabricated by Powder Bed Fusion Electron Beam Additive Manufacturing
}

\author{
Hanlin Peng ${ }^{1}{ }^{\oplus}$, Weiping Fang ${ }^{1, *}$, Chunlin Dong ${ }^{1}$, Yaoyong $\mathrm{Yi}^{1}{ }^{1}$, Xing Wei ${ }^{2}$, Bingbing Luo $^{1}$ and Siming Huang ${ }^{3}$ \\ 1 Guangdong Provincial Key Laboratory of Advanced Welding Technologies, China-Ukraine Institute of \\ Welding, Guangdong Academy of Sciences, Guangzhou 510650, China; henryhlpeng@163.com (H.P.); \\ dongchl@gwi.dg.cn (C.D.); yiyy@gwi.dg.cn (Y.Y.); lbingbing11@126.com (B.L.) \\ 2 School of Materials Science and Engineering, Huazhong University of Science and Technology, \\ Wuhan 430074, China; weixing_hust@163.com \\ 3 School of Mechanical and Automotive Engineering, South China University of Technology, \\ Guangzhou 510640, China; scutsiminghuang@163.com \\ * Correspondence: fwpln@163.com; Tel.: +86-020-61086345
}

Citation: Peng, H.; Fang, W.; Dong, C.; Yi, Y.; Wei, X.; Luo, B.; Huang, S. Nano-Mechanical Properties and Creep Behavior of Ti6Al4V Fabricated by Powder Bed Fusion Electron Beam Additive Manufacturing. Materials 2021, 14, 3004

https://doi.org/10.3390/ma14113004

Academic Editor: Katia Vutova

Received: 28 April 2021

Accepted: 26 May 2021

Published: 1 June 2021

Publisher's Note: MDPI stays neutral with regard to jurisdictional claims in published maps and institutional affiliations.

Copyright: ( $\odot 2021$ by the authors Licensee MDPI, Basel, Switzerland. This article is an open access article distributed under the terms and conditions of the Creative Commons Attribution (CC BY) license (https:// creativecommons.org/licenses/by/ $4.0 /)$.

\begin{abstract}
Effects of scanning strategy during powder bed fusion electron beam additive manufacturing (PBF-EB AM) on microstructure, nano-mechanical properties, and creep behavior of Ti6Al4V alloys were compared. Results show that PBF-EB AM Ti6Al4V alloy with linear scanning without rotation strategy was composed of $96.9 \% \alpha$-Ti and $2.7 \% \beta$-Ti, and has a nanoindentation range of 4.11-6.31 GPa with the strain rate ranging from 0.001 to $1 \mathrm{~s}^{-1}$, and possesses a strain-rate sensitivity exponent of $0.053 \pm 0.014$. While PBF-EB AM Ti6Al4V alloy with linear and $90^{\circ}$ rotate scanning strategy was composed of $98.1 \% \alpha$-Ti and $1.9 \% \beta$-Ti and has a nanoindentation range of 3.98-5.52 GPa with the strain rate ranging from 0.001 to $1 \mathrm{~s}^{-1}$, and possesses a strain-rate sensitivity exponent of $0.047 \pm 0.009$. The nanohardness increased with increasing strain rate, and creep displacement increased with the increasing maximum holding loads. The creep behavior was mainly dominated by dislocation motion during deformation induced by the indenter. The PBF-EB AM Ti6Al4V alloy with only the linear scanning strategy has a higher nanohardness and better creep resistance properties than the alloy with linear scanning and $90^{\circ}$ rotation strategy. These results could contribute to understanding the creep behavior of Ti6Al4V alloy and are significant for PBF-EB AM of Ti6Al4V and other alloys.
\end{abstract}

Keywords: titanium alloys; electron beam additive manufacturing; nanoindentation; strain rate sensitivity; creep

\section{Introduction}

In recent years, additive manufacturing (AM) has attracted extensive attention and has great potential to be used in the fields of aerospace, automotive, energy, and medicine [1-3]. Powder bed fusion with electron beam (PBF-EB) AM is one of the AM methods, using a high-energy electron beam as a heat source to melt metal powders and then obtaining full-dense metallic components [4]. Compared with the selective laser melting (SLM) AM method, PBF-EB AM has several advantages [5]: (1) High vacuum condition is favorable for materials containing active elements; (2) high energy input is favorable for refractory materials. It has been reported that PBF-EB AM has been applied in fabricating highentropy alloys [6], titanium alloys [7], and ceramics [8].

Due to their superior mechanical properties, excellent corrosion resistance, and outstanding biocompatibility, Ti6Al4V alloys have been used as biomedical implants and aviation materials [9-12]. However, the inherent difficulties in plastic processing and specific components with complex geometry make Ti6Al4V an attractive material for AM. The abrasion, fatigue, or impact properties of Ti6Al4V alloys could be further improved 
through AM $[13,14]$. In comparison with other AM methods, PBF-EB AM is the most widely-used process for producing Ti-based components because of their extremely high sensitivity to oxidation at high fabrication temperatures [15-18]. For AM Ti6Al4V alloys, the most attention is focused on the effects of PBF-EB AM parameters, post-treatment on microstructure, and mechanical properties. Tan et al. [19] investigated the columnar grain growth behavior of Ti6Al4V alloy during the PBF-EB AM process. Leon et al. [9] improved the mechanical properties of PBF-EB AM Ti6Al4V alloys using hot isostatic pressing post-treatment. Zheng et al. [20] investigated the effects of powder usage numbers on the hardness of PBF-EB AM Ti6Al4V alloys.

To date, only a few studies have been done to comprehensively assess the creep behavior of Ti6Al4V alloys [21]. However, the creep behavior is not completely understood. Investigation of creep behavior by traditional uniaxial tensile tests is time-consuming for lots of materials [22]. Nanoindentation tests are confirmed to be effective in analyzing the time-dependent plastic deformation of aluminum [23,24], high-entropy alloys [25,26], titanium alloys [27], and $\mathrm{Ni}_{3} \mathrm{Al}$ [28]. Although there is a bit of discrepancy between the indentation creep results and conventional uniaxial results [29-31], creep information including strain rate sensitivity, the creep stress exponent, and creep rate could be obtained based on the nanoindentation creep test [30,32]. Shen et al. claimed the discrepancy between nanoindentation and uniaxial methods results from the deformation mechanics [33]. The response from indentation creep tests thus includes the transient stage as well as the steady-state, or even post steady-state stages, which is more complex than that from uniaxial tests.

Wu et al. [34] found that the scanning strategy during selective laser melting AM has a great influence on residual stress of Ti6Al4V alloys. Tian et al. [35] reported that microstructure and mechanical properties of Ti6Al4V alloys could be influenced by the scanning strategy during selective laser melting AM. However, the reports on the effects of the scanning strategy during PBF-EB AM on nano-mechanical properties and creep behavior of Ti6Al4V alloys are rarely seen. Therefore, in this study, the effects of the scanning strategy during PBF-EB AM on microstructure, nanohardness, strain rate sensitivity, and creep behavior of Ti6Al4V are investigated.

\section{Materials and Methods}

\subsection{Powder Preparation}

Spherical Ti6Al4V powders with an average size of $76 \mu \mathrm{m}$ were provided by the supplier, Guangzhou Sailong Additive Manufacturing Co. LTD., Guangzhou, China, which was fabricated by plasma rotating electrode methods. Powder size distribution was characterized by a laser particle analyzer (MASTERSIZER 3000, Malvern, UK). A scanning electron microscope (SEM, ZEISS, Gemini SEM300, Oberkochen, Germany) equipped with energy-dispersive X-ray spectroscopy (EDS, Bruker, Billerica, MA, USA) was used to evaluate the chemical composition accuracy. The SEM morphology and particle size distribution of the as-received powders are shown in Figure 1a,b, respectively. The corresponding chemical composition was determined to be $5.85 \pm 0.4 \mathrm{Al}, 4.12 \pm 0.24 \mathrm{~V}$ (wt.\%), and balanced with Ti. 

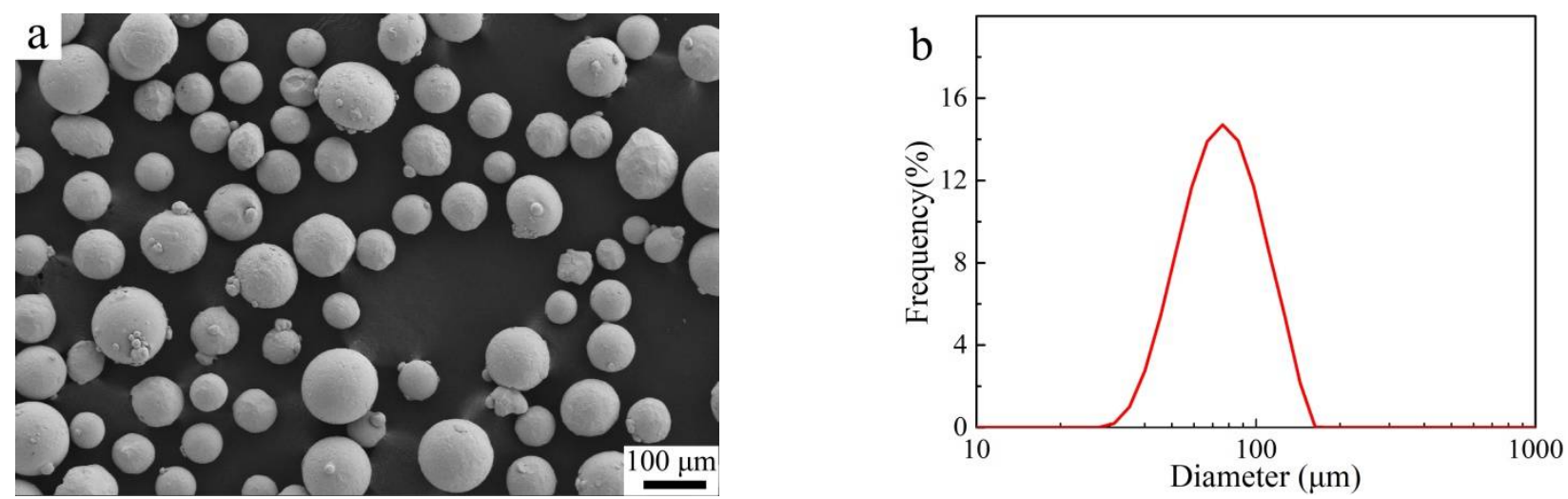

Figure 1. (a) SEM morphology and (b) particle size distribution of the as-received powders.

\subsection{EB-PBF Processing}

The cuboid-shaped sample with dimensions of $25 \mathrm{~mm} \times 100 \mathrm{~mm} \times 50 \mathrm{~mm}$ was produced using a T150 powder bed fusion electron beam additive manufacturing machine (Guangzhou Sailong Additive Manufacturing Co. LTD., Guangzhou, China). Plasma rotating electrode Ti6Al4V powders (mean diameter of $76 \mu \mathrm{m}$ ) were applied at a layer thickness of $50 \mu \mathrm{m}$. During the PBF-EB additive manufacturing, a scan speed of $5800 \mathrm{~mm} / \mathrm{s}$, a high voltage of $60 \mathrm{kV}$, a current of $14.5 \mathrm{~mA}$, and a space of $100 \mu \mathrm{m}$ between scan lines were adopted. The preheating temperature was kept at $730^{\circ} \mathrm{C}$ for all of the samples to avoid powder smoke. Two scanning strategies were used in this study (details can be seen in Figure 2): (1) case (a) is horizontal back and forth linear scanning without rotation on the next layer, and the corresponding sample was referenced as sample A; (2) case (b) is horizontal back and forth linear scanning with a $90^{\circ}$ scan vector rotation on the next layer, and the corresponding sample was referenced as sample B.

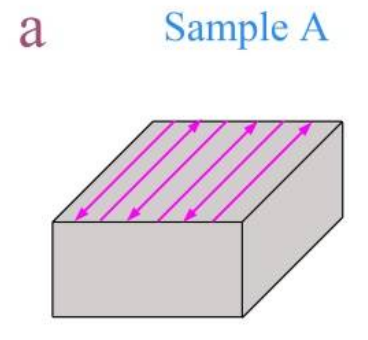

b Sample B

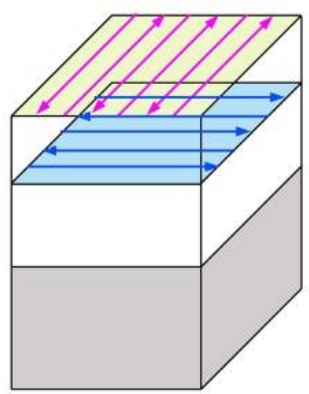

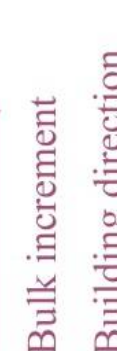
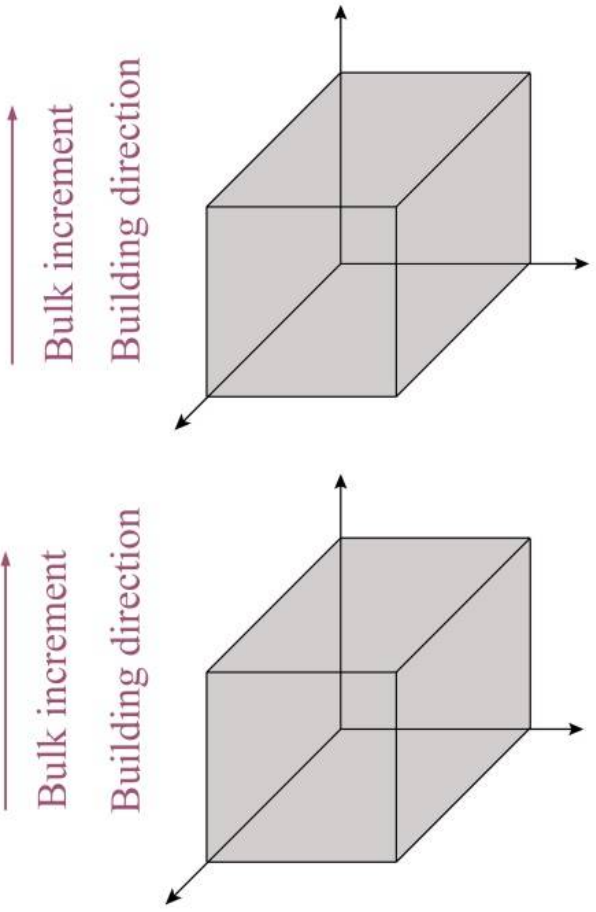

Figure 2. Schematic diagrams of building direction for PBF-EB AM Ti6Al4V alloys: (a) Sample A is horizontal back and forth linear scanning without rotation on the next layer; (b) Sample B is horizontal back and forth linear scanning with a $90^{\circ}$ scan vector rotation on the next layer. 


\subsection{XRD Analysis}

The block samples were cut along the building direction Z-axis using a wire electric discharge machine, $2 \mathrm{~mm}$ away from the base, and subsequently embedded for microstructural investigation and nanoindentation tests on the $X-Y$ plane. The cross-sectioned samples were consecutively ground by \#100, \#600, \#800, \#1200, \#1500, and \#2000 grade silicon carbide papers to remove any surface oxides. Then ground samples were consecutively polished with $5 \mu \mathrm{m}, 3 \mu \mathrm{m}, 2 \mu \mathrm{m}, 1 \mu \mathrm{m}$, and $0.5 \mu \mathrm{m}$ grade diamond abrasive paste. Phase constituents were examined by X-ray diffraction (XRD, D/MAX-2500/PC; Rigaku Corp., Tokyo, Japan) with Mo K $\alpha$ radiation. The angle range of $15-45^{\circ}$ and a step size of $0.01^{\circ}$ was adopted during the XRD test. More details can be seen in our previous research [36].

\subsection{SEM Analysis}

Before SEM observation, the polished block samples were etched with Kroll's reagent $\left(2 \% \mathrm{HF}, 6 \% \mathrm{HNO}\right.$, and $92 \% \mathrm{H}_{2} \mathrm{O}$ ) for $5 \mathrm{~s}$. The microstructure of the PBF-EB Ti6Al4V sample was observed by scanning electron microscope (SEM, FEI, QUANT250, Eindhoven, The Netherlands) equipped with energy-dispersive X-ray spectroscopy (EDS), with a working distance (WD) of $9.8 \mathrm{~mm}$ and high voltage of $10.00 \mathrm{kV}$. Additionally, the morphology and chemical composition of the raw powders were observed by scanning electron microscope (SEM, ZEISS, Gemini SEM300, Oberkochen, Germany) equipped with energy-dispersive X-ray spectroscopy (EDS, Bruker, Billerica, MA, USA). After the samples were electrolytically polished with $5 \%$ perchloric acid $+95 \%$ alcohol and electron backscattered diffraction (EBSD, FEI, Hillsboro, OR, USA) tests were performed to further investigate the microstructure. During the EBSD test, a step size of $0.1 \mu \mathrm{m}$ was adopted for low magnification, and a step size of $0.01 \mu \mathrm{m}$ was adopted for high magnification. During the EBSD test, a high voltage of $10.00 \mathrm{kV}$ was used.

\subsection{Nanoindentation Analysis}

The nanomechanical properties and creep behavior of the PBF-EB AM Ti6Al4V alloys were characterized by nanoindentation tests (Hysitron, T1980, Minneapolis, mN, USA). All the tests were conducted at room temperature and performed with a three-sided Berkovich (CSM Instruments, Peuseux, Switzerland) diamond indenter. For investigation of the strain rate sensitivity, all nanoindentation tests were carried out at the same maximum load $(10 \mathrm{mN})$ and with loading rates of $10,1,0.1$, and $0.01 \mathrm{mN} / \mathrm{s}$. The indenter was then held at the maximum load for $30 \mathrm{~s}$, which was followed by unloading at a rate of $50 \mathrm{mN} / \mathrm{s}$ for all tests. For investigation of creep behavior, the specimen was loaded to different maximum loads, Pmax $(10 \mathrm{mN}, 20 \mathrm{mN}, 50 \mathrm{mN}$, and $100 \mathrm{mN})$, at a successive loading rate of $0.5 \mathrm{mN} / \mathrm{s}$ and held at Pmax for $500 \mathrm{~s}$.

\section{Results}

\subsection{Microstructure}

XRD patterns of PBF-EB AM Ti6Al4V alloys (X-Y plane) arre shown in Figure 3, both for sample A with linear scanning strategy, and sample B with linear and $90^{\circ}$ rotation scanning strategy. The XRD pattern confirms the dominant presence of an $\alpha$-Ti phase, and this result is similar to the previous work [9]. Comparing the XRD results in Figure 3a,b, a tiny difference could be observed. For the XRD pattern of sample A (Figure 3a), the intensity of $(10 \overline{1} 2),(10 \overline{1} 3)$, and (11ㄹㄹ) diffraction peaks belonging to the $\alpha$-Ti phase are stronger than those of sample B. This result indicates that the scanning strategy of PBF-EB AM probably leads to a difference in the texture of Ti6Al4V alloys. 

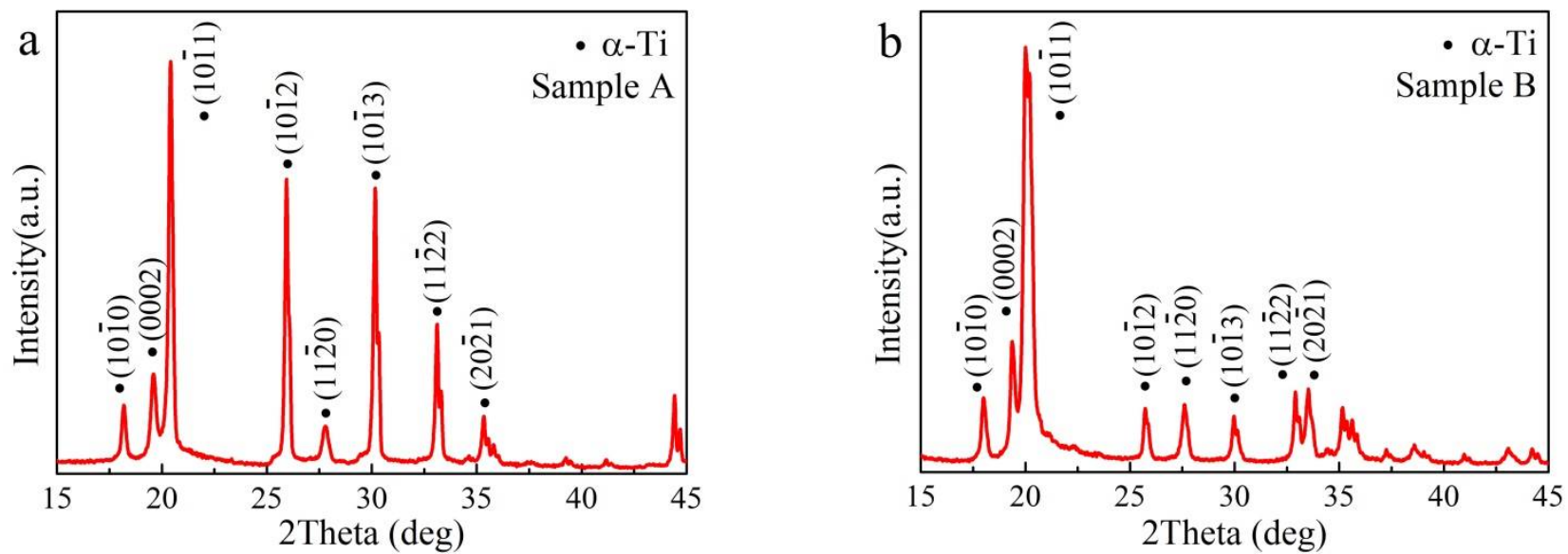

Figure 3. XRD pattern of PBF-EB AM Ti6Al4V alloy: (a) linear scanning strategy (sample A), (b) linear and $90^{\circ}$ rotation scanning strategy (sample B).

As widely known, the microstructure of Ti6Al4V alloy consists of $\alpha$-Ti and $\beta$-Ti phases [37]. During the PBF-EB AM process, the Ti6Al4V alloy originally solidifies into columnar $\beta$-Ti grains that grow along the build direction. As the additive manufactured alloys cool to a temperature below around $882{ }^{\circ} \mathrm{C}$, the $\beta$-Ti grains boundaries act as nucleation sites for $\alpha$-Ti grains, and the initial $\beta$-Ti within the grains transforms into $\alpha / \beta$ lamellar structures. This process promotes the development of $\beta$-Ti ribs surrounded by a continuous $\alpha$-Ti phase [38]. The microstructures of sample A and sample B are shown in Figure $4 a, b$, respectively. It can be seen that the thickness of $\beta$-Ti ribs in sample $B$ is smaller than those in sample A. Furthermore, $\beta$-Ti ribs in both sample A and sample B have a thickness of few than $1 \mu \mathrm{m}$.
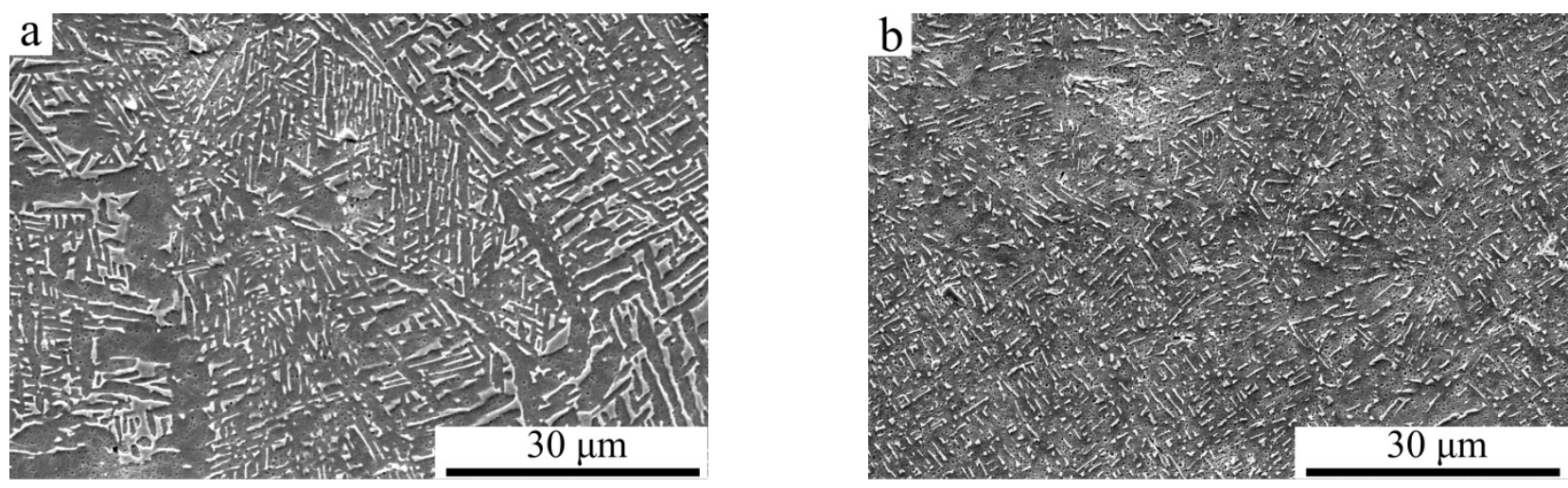

Figure 4. SEM microstructure of PBF-EB AM Ti6Al4V: (a) linear scanning strategy (sample A), (b) linear and $90^{\circ}$ rotate scanning strategy (sample B).

The chemical composition of the a-Ti phase and $\beta$-Ti ribs in both sample A and sample $\mathrm{B}$ are listed in Table 1 . The results are obtained by SEM/EDS. As widely known, $\mathrm{Al}$ is an $\alpha$ phase stabilizing element and usually diffused into $\alpha$ phase, while $V$ is a $\beta$ phase stabilizing element and usually diffused into the $\beta$ phase $[39,40]$. It can be seen that there is no obvious enrichment or depth of $\mathrm{Al}$ and $\mathrm{V}$ elements in the $\alpha / \beta$ phase. For sample B, both the $\mathrm{Al}$ and $\mathrm{V}$ concentration in $\alpha$ phase and $\beta$ ribs is very similar. 
Table 1. Chemical composition of $\alpha$-Ti phase and $\beta$-Ti ribs in PBF-EB AM Ti6Al4V with different scanning strategies.

\begin{tabular}{ccccc}
\hline \multirow{2}{*}{$\begin{array}{c}\text { Chemical } \\
\text { Composition }\end{array}$} & \multicolumn{2}{c}{ Sample A } & \multicolumn{2}{c}{ Sample B } \\
\cline { 2 - 5 } & $\boldsymbol{\alpha}$-Ti (wt\%) & $\boldsymbol{\beta}$-Ti ribs (wt \%) & $\boldsymbol{\alpha}$-Ti (wt \%) & $\boldsymbol{\beta}$-Ti ribs (wt \%) \\
\hline $\mathrm{Al}$ & $5.48 \pm 0.64$ & $5.86 \pm 0.50$ & $5.48 \pm 0.07$ & $5.32 \pm 0.65$ \\
$\mathrm{~V}$ & $4.05 \pm 2.55$ & $2.83 \pm 0.54$ & $3.22 \pm 0.66$ & $2.93 \pm 0.66$ \\
$\mathrm{Ti}$ & $90.48 \pm 1.92$ & $91.32 \pm 0.04$ & $91.2 \pm 0.59$ & $90.25 \pm 2.14$ \\
\hline
\end{tabular}

Since the conditions of heat accumulation and conduction are tightly linked to scanning strategies and relative position of the sample $[4,34,41]$, the $X-Y$ cross-section plane, $2 \mathrm{~mm}$ away from the base, was chosen for EBSD observation. Grain morphology and corresponding inverse pole figure (IPF) are shown in Figure 5a,b, respectively. The average grain size of the $\alpha$-Ti phase is $2.3 \mu \mathrm{m}$, as shown in Figure 5c. To analyze the effects of scanning strategy on phase constitution of the PBF-EB AM Ti6Al4V alloy, a region with high magnification and a smaller step size $(0.01 \mu \mathrm{m})$ was selected. The corresponding results are shown in Figure 5c,d. The phase maps are shown in Figure 5d. It can be seen that the PBF-EB AM Ti6Al4V alloy with only the linear scanning strategy (sample A) was composed of $96.9 \% \alpha$-Ti and $2.7 \% \beta$-Ti.
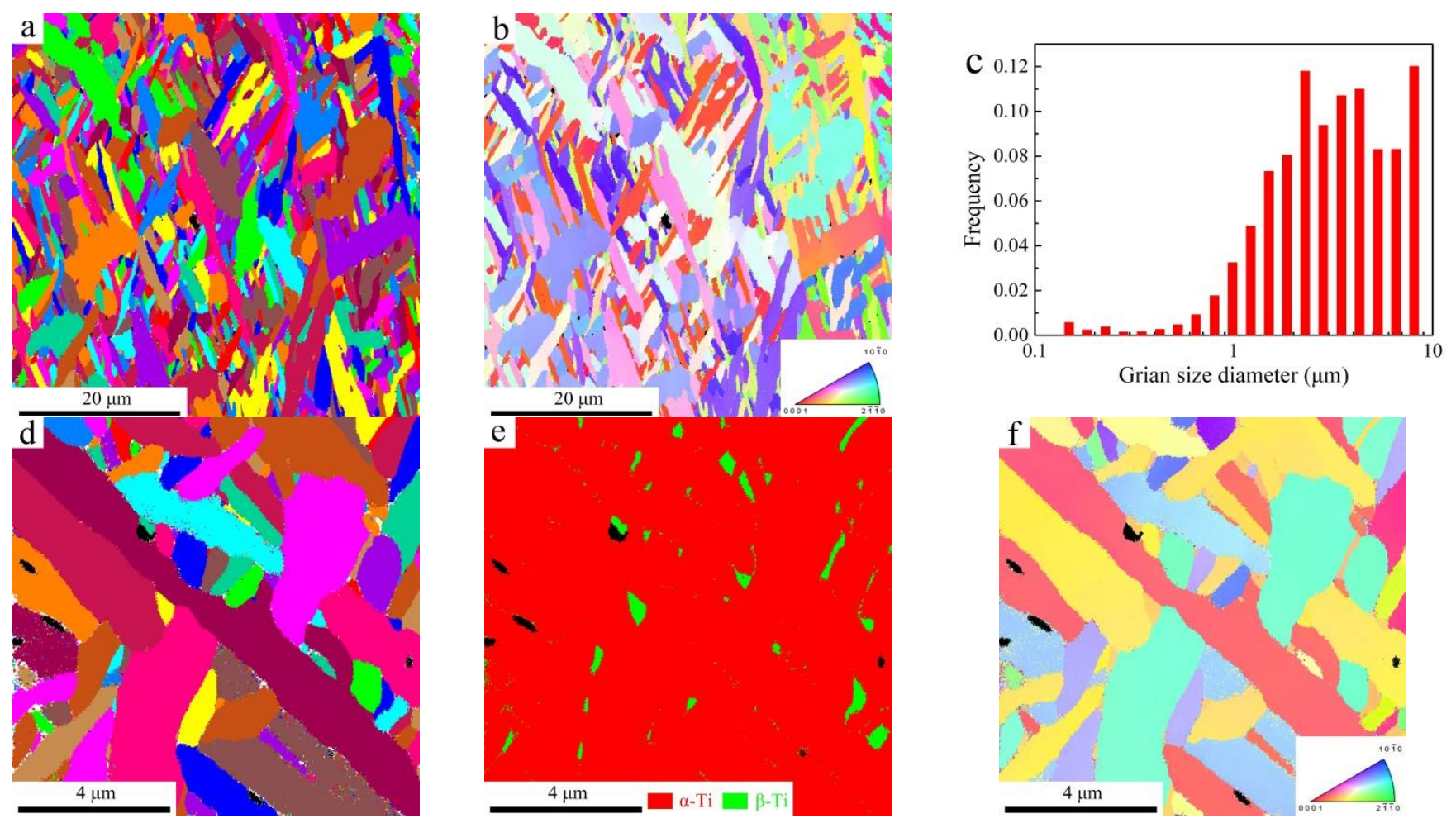

Figure 5. PBF-EB AM Ti6Al4V alloy with only the linear scanning strategy (sample A): (a) Grain size and (b) IPF images at low magnification; (c) grain size, (d) phase map, and (e) IPF figures at high magnification. The color of the inset figure in $(\mathbf{b}, \mathbf{f})$ represents grains orientation.

For the PBF-EB AM Ti6Al4V alloy with linear and $90^{\circ}$ rotation scanning strategy (sample B), the EBSD observation results are shown in Figure 6. From Figure 6c, it can be seen that the average thickness of the $\alpha$-Ti phase is $2.5 \mu \mathrm{m}$. A high magnification was chosen with a step size of $0.01 \mu \mathrm{m}$. Additionally, the results are shown in Figure 6c,d. From the phase map (Figure 6e), it can be seen that the PBF-EB AM Ti6Al4V alloy with linear and $90^{\circ}$ rotation scanning strategy (sample B) was composed of $98.1 \% \alpha$-Ti and $1.9 \%$ $\beta$-Ti. Compared with sample B, the $\alpha$-Ti phase contents in sample A are a bit lower, while 
the $\beta$-Ti phase contents in sample $\mathrm{A}$ are a bit higher. The results indicate that scanning strategies during additive manufacturing could affect heat accumulation and conduction, and then influence the microstructure and mechanical properties.
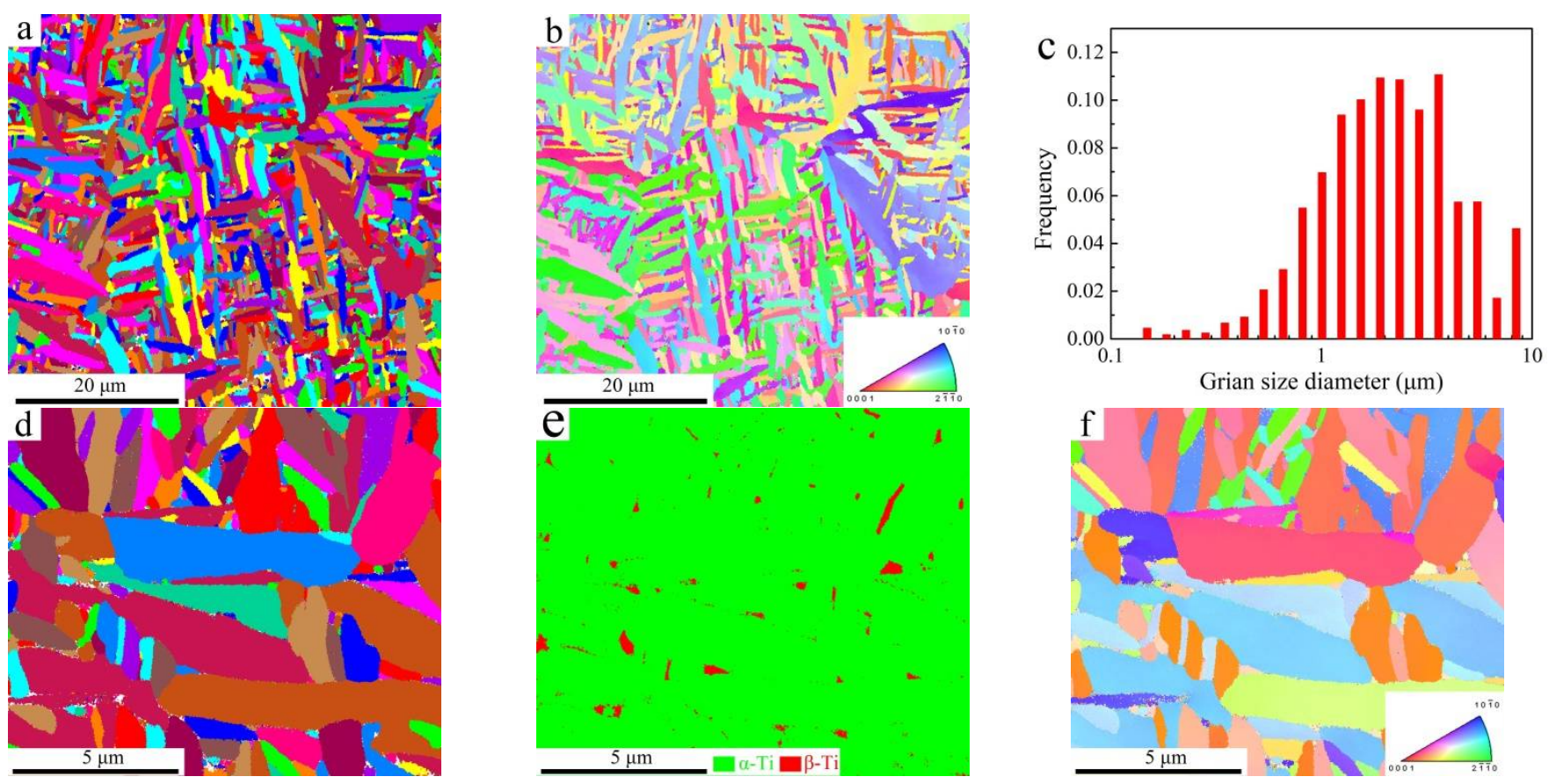

Figure 6. PBF-EB AM Ti6Al4V alloy with linear and $90^{\circ}$ rotate scanning strategy (sample B): (a) Grain size and (b) IPF images at low magnification; (c) grain size, (d) phase map, and (e) IPF figures at high magnification. The color of the inset figure in $(\mathbf{b}, \mathbf{f})$ represents grains orientation.

From the EBSD analysis, the average size of the $\alpha$-Ti phase in sample $\mathrm{A}$ is very similar to the $\alpha$-Ti phase in sample A. Hence, the grain boundary strengthening is very similar due to the similar thickness of the $\alpha$-Ti phase [42]. However, the solid solution strengthening is different. From Table 1, it can be seen that Al concentration in the $\alpha$-Ti phase is similar in both samples. However, the $\mathrm{V}$ concentration in the $\alpha$-Ti phase from sample $\mathrm{A}$ is higher than the value from sample B. Therefore, high $V$ concentration in the $\alpha$-Ti phase would lead to higher hardness.

\subsection{Strain-Rate Sensitivity}

Before the nanoindentation test, the Archimedes principle was employed to measure the porosity of PBF-EB AM Ti6Al4V alloys. The densities of sample A and sample B were $98.52 \%$ and $98.22 \%$, respectively. It can be seen that the scanning strategy has little influence on the porosity of Ti6Al4V alloys under the selected additive manufacturing parameters.

Figure 7 shows the typical load-depth curves for the PBF-EB AM Ti6Al4V alloy as obtained from nanoindentation tests under various loading rates. All nanoindentation tests were carried out at the same maximum load $(10 \mathrm{mN})$. Loading rates of $0.01 \mathrm{mN} / \mathrm{s}$, $0.1 \mathrm{mN} / \mathrm{s}, 1 \mathrm{mN} / \mathrm{s}$, and $10 \mathrm{mN} / \mathrm{s}$ were applied, corresponding to strain rates of $0.001 \mathrm{~s}^{-1}$, $0.01 \mathrm{~s}^{-1}, 0.1 \mathrm{~s}^{-1}$, and $1 \mathrm{~s}^{-1}$, respectively. As shown in Figure 7, the loading rates result in different depths. The depth increases significantly with the decreasing strain rate (or loading rates). Results from nanoindentation tests under different strain rates are presented in Table 2. It can be seen that as the strain rate increases in the range of $0.001-1 \mathrm{~s}^{-1}$, the hardness increases between 4.11 and $6.31 \mathrm{GPa}$ for sample A. While for sample B, as the strain rate increases in the range of $0.001-1 \mathrm{~s}^{-1}$, the hardness increases between 3.98 and $5.52 \mathrm{GPa}$. The results indicate that the PBF-EB AM Ti6Al4V alloy with only the linear 
scanning strategy has higher nanohardness than the alloy with a $90^{\circ}$ rotation scanning strategy.
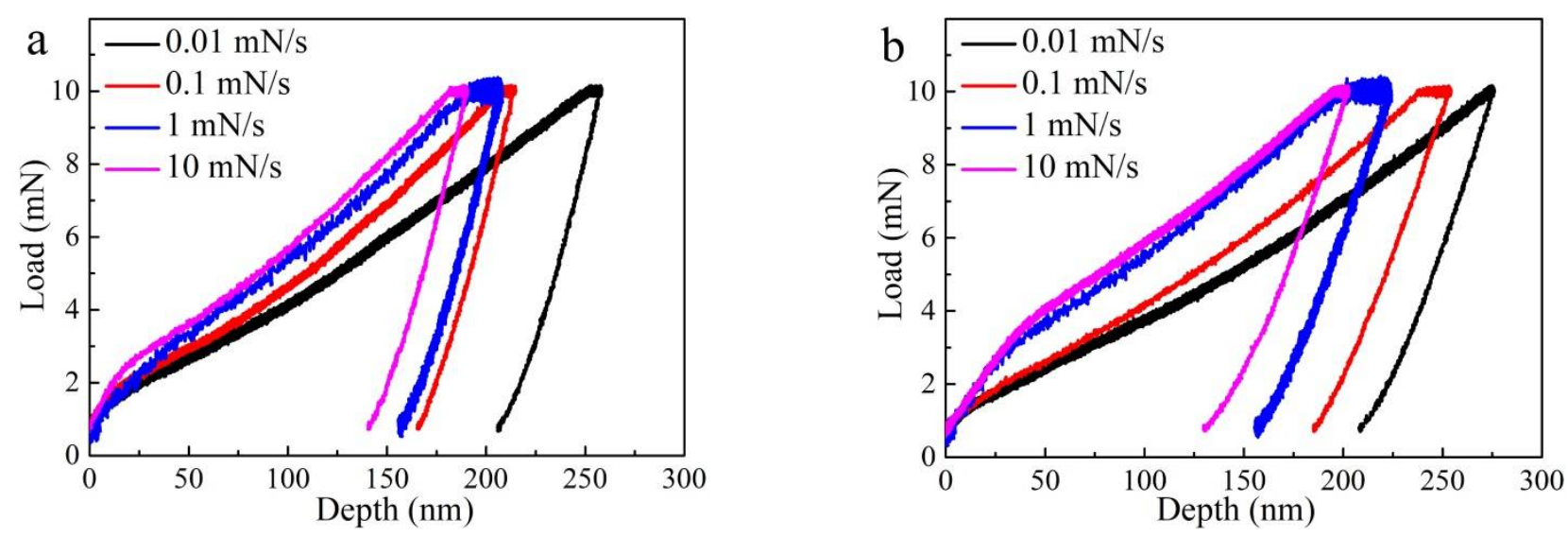

Figure 7. Typical load-depth curve with various strain rates at the same Pmax $=10 \mathrm{mN}$. (a) Linear scanning strategy (sample A), (b) linear and $90^{\circ}$ rotation scanning strategy (sample A).

Table 2. Various loading rates, strain rates, and corresponding nanohardnesses for PBF-EB AM Ti6Al4V alloys with different scanning strategies.

\begin{tabular}{cccc}
\hline \multirow{2}{*}{ Loading Rate $(\mathbf{m N} / \mathbf{s})$} & Strain Rate $\left(\mathbf{s}^{-\mathbf{1}}\right)$ & \multicolumn{2}{c}{ Hardness (GPa) } \\
\cline { 3 - 4 } & & Sample A & Sample B \\
\hline 0.01 & 0.001 & 4.11 & 3.98 \\
0.1 & 0.01 & 5.4 & 4.33 \\
1 & 0.1 & 5.54 & 4.59 \\
10 & 1 & 6.31 & 5.52 \\
\hline
\end{tabular}

The relationship between indentation nanohardness and strain rate could be expressed by Equation (1):

$$
\mathrm{H}=C \dot{\varepsilon}^{m}
$$

where $\mathrm{H}$ is the nanohardness (GPa), $\mathrm{C}$ is the material constant, $\dot{\varepsilon}$ is the strain rate $\left(\mathrm{s}^{-1}\right)$, and $m$ is the strain rate sensitivity exponent [43]. Therefore, the strain-rate sensitivity exponent can be determined by the slope of an $\ln \mathrm{H}$ vs. $\ln \dot{\varepsilon}$ plot.

The relationship between indentation nanohardness $(\mathrm{H})$ and strain rate $(\dot{\varepsilon})$ is shown in Figure 8. The equations in Figure 8a,b indicate that the relationship between $\mathrm{H}$ and $\dot{\varepsilon}$ has a high correlation coefficient, $R^{2}=0.83$, and $R^{2}=0.9$ for sample A and sample $B$, respectively. The results implied that this function can properly measure the dependence of the nanoindentation hardness on the strain rate. Based on the Figure 8, the strain-rate sensitivity exponent $(m)$ are determined to be $0.053 \pm 0.014$ and $0.047 \pm 0.009$ for sample A and sample B, respectively.

The strain-rate sensitivity exponent $(m)$ is important to evaluate the super-plasticity of materials. The strain-rate sensitivity exponent $(m)$ of superplastic materials usually exceeds 0.3 [44]. The value of $m(0.053 \pm 0.014$ and $0.047 \pm 0.009)$ in this study does not exceed 0.1 , which is similar to that of the most known materials. Yu et al. [43] determined the strain-rate sensitivity exponent of $\mathrm{H} 13$ tool steel to be 0.022 using nanoindentation. Jun et al. [27] characterized the strain-rate sensitivity exponent of Ti6246 alloys to be $0.005-0.039$ via nanoindentation test. 

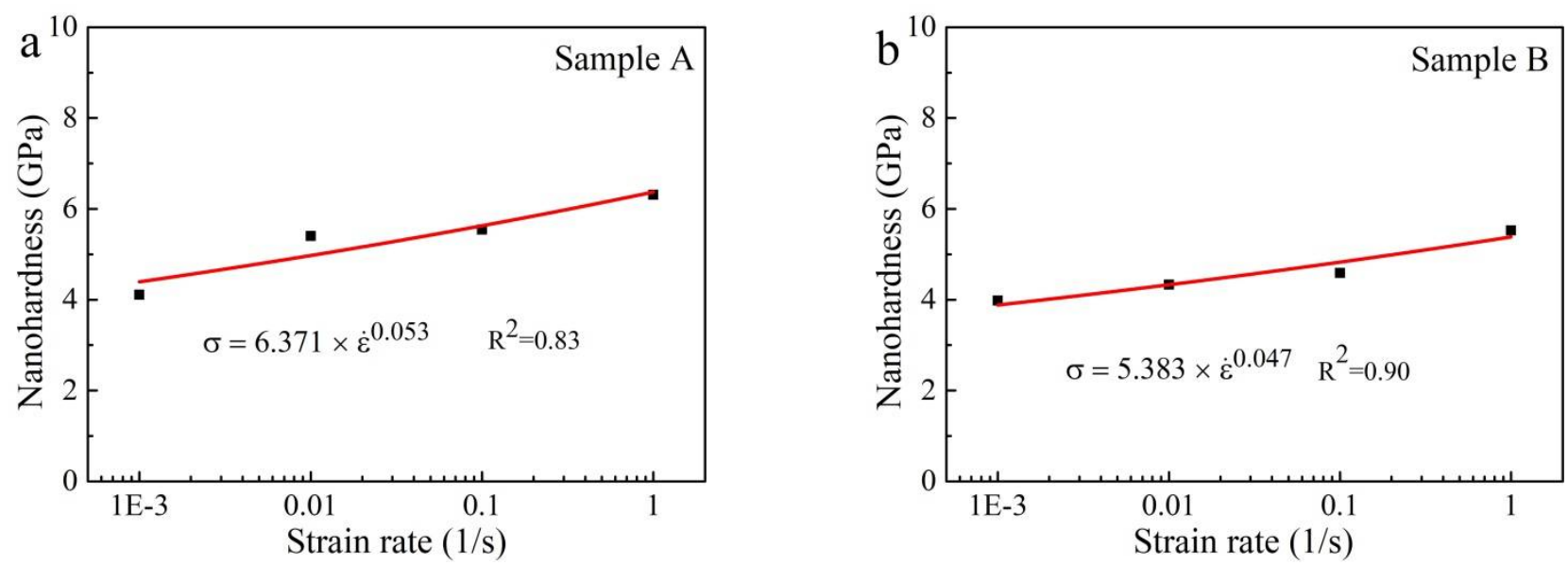

Figure 8. Representative nanohardness as a function of strain rate: (a) Linear scanning strategy (sample A) and the slope has a standard error of $0.327,(\mathbf{b})$ linear and $90^{\circ}$ rotation scanning strategy (sample B) and the slope has a standard error of 0.181 .

\subsection{Creep Behavior}

For PBF-EB AM Ti6Al4V alloys with different scanning strategies, the typical loaddisplacement $(\mathrm{P}-\mathrm{h})$ curves under various maximum holding loads (Pmax) ranging from 10 to $100 \mathrm{mN}$ are shown in Figure 9a. The curves consist of the loading stage, holding stage (creep stage), and unloading stage. It can be seen that plastic deformation occurred before the holding stage and the displacement increases during the holding stage. With the maximum holding load (Pmax) increased from 10 to $100 \mathrm{mN}$, the creep displacement dramatically increased. When the unloading is finished, the deformation is not completely recovered and indentation depth remains a large value. The nanoindentation results confirm the occurrence of creep behavior, despite the loading stress being very low at room temperature.

The creep behavior induced by the nanoindentation test has been explored by several scholars, and the creep displacement $(h, \mathrm{~nm})$ and holding time $(t, \mathrm{~s})$ could be depicted as follows $[25,28,32]$ :

$$
h=h_{0}+a\left(t-t_{0}\right)^{\mathrm{b}}+k t
$$

where $h_{0}, a, t_{0}, \mathrm{~b}$, and $k$ are constant and can be obtained by fitting the creep displacement (h) and holding time $(t, \mathrm{~s}), h_{0}(\mathrm{~nm})$, and $t_{0}(\mathrm{~s})$ refers to the displacement and time at the beginning stage of creep, respectively. After obtaining the relationship between creep displacement $(h, \mathrm{~nm})$ and holding time $(t, \mathrm{~s})$, the indentation strain rate $\left(\dot{\varepsilon}, \mathrm{s}^{-1}\right)$ can be obtained according to the equation below [31]:

$$
\dot{\varepsilon}=\frac{1}{h} \frac{\mathrm{dh}}{\mathrm{dt}}
$$

where displacement rate $(\mathrm{dh} / \mathrm{dt}, \mathrm{nm} / \mathrm{s})$ could be obtained by derivating the displacementholding time $(h-t)$. The nanoindentation stress $(\mathrm{H}, \mathrm{GPa})$ could be expressed as $\mathrm{H}=\mathrm{P} / h^{2}$, in which $\mathrm{P}(\mathrm{mN})$ denotes the holding load and $\mathrm{h}(\mathrm{nm})$ refers to the indentation displacement. Then the creep stress exponent $(n)$ could be calculated by the empirical equation below [25]:

$$
n=\frac{\partial \ln \dot{\varepsilon}}{\partial \ln H}
$$

The experimental variations of displacement with time are shown in Figure 9b, corresponding to the holding stage in Figure 9a. Based on Equation (2), the fitting results of creep displacement $(h)$-time $(t)$ curves are clearly shown in Figure $9 \mathrm{c}$ and a high correlation coefficient $\left(R^{2}>0.9\right)$ is obtained. From both experimental and fitting creep displacement-time results, it can be observed that the displacement increased dramatically with increasing 
loads. The creep displacement has a value of around $15 \mathrm{~nm}, 30 \mathrm{~nm}, 75 \mathrm{~nm}$, and $95 \mathrm{~nm}$, corresponding to the maximum holding load, Pmax, of $10 \mathrm{mN}, 20 \mathrm{mN}, 50 \mathrm{mN}$, and $100 \mathrm{mN}$, respectively. According to Equations (2)-(4), the creep stress exponent $(n)$ under various indentation loads is shown in Figure $9 \mathrm{~d}$. The value of the creep stress exponent $(n)$ decreased with the increasing maximum holding loads, Pmax, (10-100 mN).
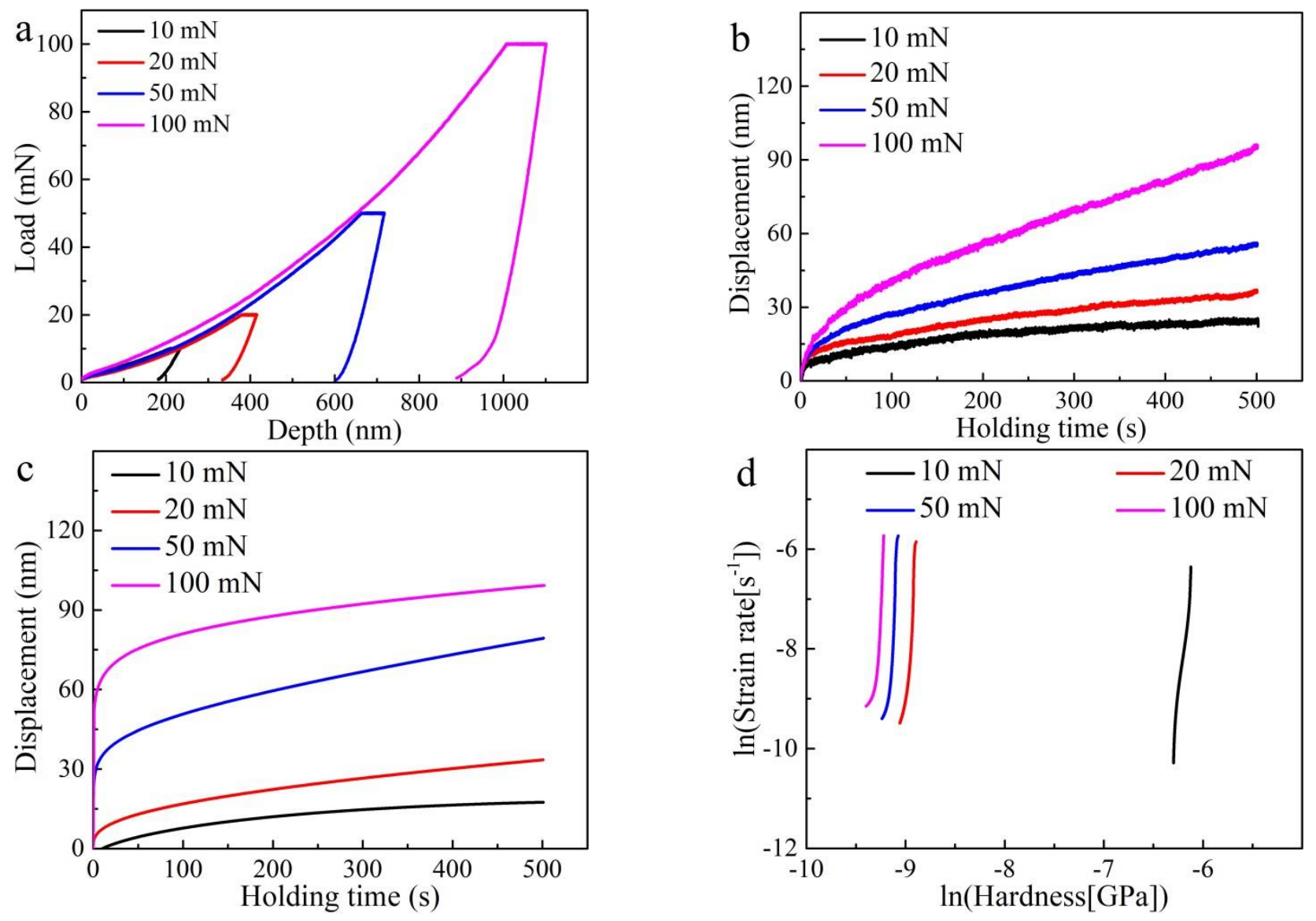

Figure 9. PBF-EB AM Ti6Al4V alloy with only the linear scanning strategy (sample A): (a) P-h curves under various maximum loads (10-100 $\mathrm{mN}$ ); (b) experimental and (c) fitting creep displacement-time curves under various maximum loads (10-100 mN); (d) ln-ln plots of strain rate vs. nanoindentation stress under various maximum loads (10-100 mN).

For PBF-EB AM Ti6Al4V alloy with linear and $90^{\circ}$ rotate scanning strategy (sample B), the typical load-displacement $(\mathrm{P}-\mathrm{h})$ curves under various peak loads ranging from 10 to $100 \mathrm{mN}$ are shown in Figure 10a. The experimental and fitting creep displacement-time curves under various maximum loads $(10-100 \mathrm{mN})$ are shown in Figure $10 \mathrm{~b}, \mathrm{c}$, respectively. When fitting the creep displacement-time curves based on Equation (2), there is a high correlation coefficient $\left(R^{2}>0.9\right)$. When the maximum holding load (Pmax) increased from 10 to 20,50, and $100 \mathrm{mN}$, the creep displacement had a values of around $25 \mathrm{~nm}$, $85 \mathrm{~nm}, 170 \mathrm{~nm}$, and $225 \mathrm{~nm}$, respectively. Figure 10d shows the $\mathrm{ln}-\mathrm{ln}$ plots of strain rate vs. nanoindentation stress under various maximum loads $(10-100 \mathrm{mN})$. The value of the creep stress exponent $(n)$ decreased with the increasing maximum holding loads, Pmax, $(10-100 \mathrm{mN})$. 

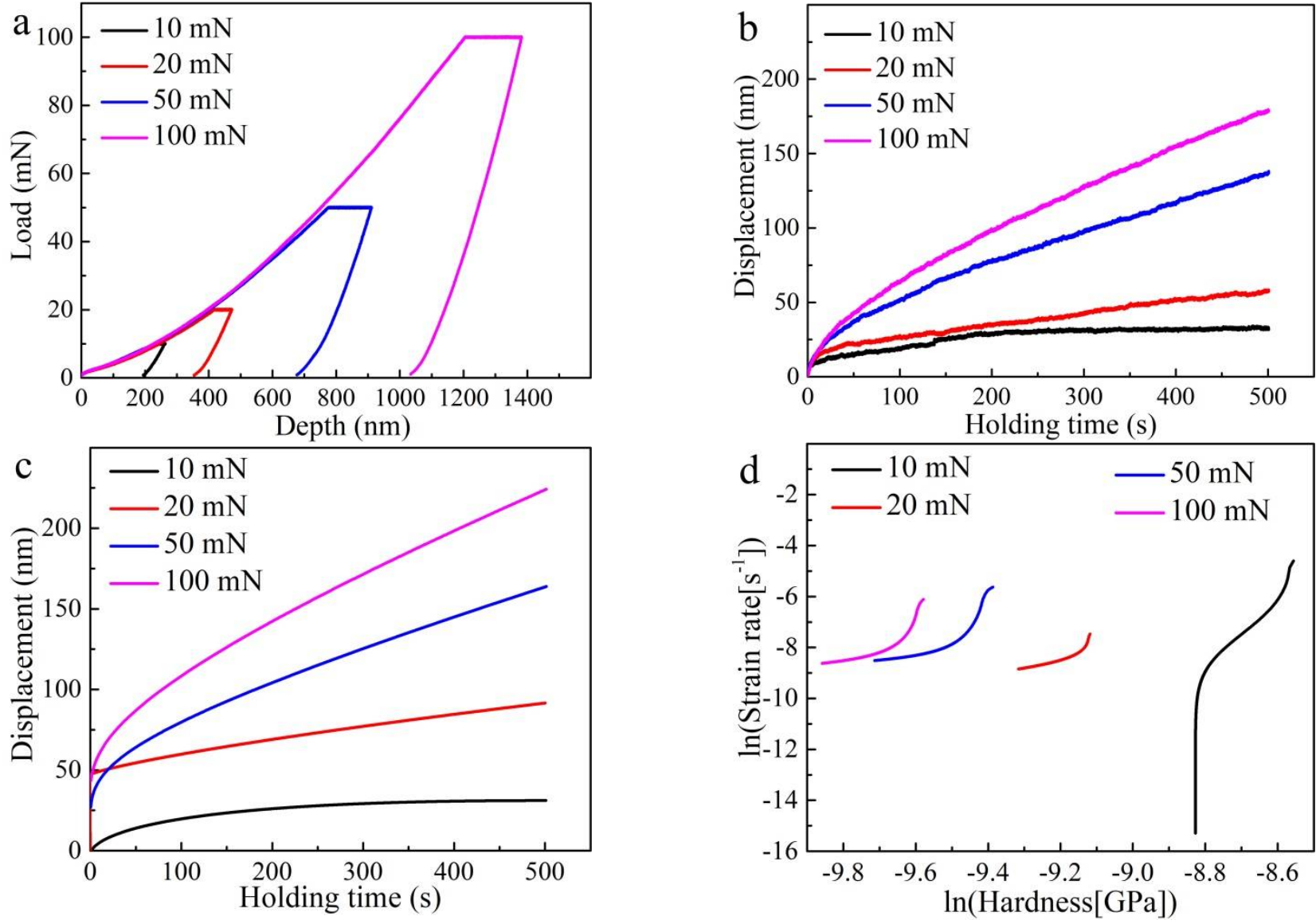

Figure 10. PBF-EB AM Ti6Al4V alloy with linear and $90^{\circ}$ rotation scanning strategy (sample B): (a) P-h curves under various maximum loads (10-100 $\mathrm{mN}$ ); (b) experimental and (c) fitting creep displacement-time curves under various maximum loads (10-100 mN); and (d) $\ln$-ln plots of strain rate vs. nanoindentation stress under various maximum loads (10-100 mN).

From both Figure $9 b, c$ and Figure 10b,c, it can be seen that the creep curves from the nanoindentation test have transient-state creep and steady-state creep stages. As widely known, the classic creep curves obtained from uniaxial tensile tests have transient-state creep, steady-state creep, and accelerated creep stages [45,46]. This difference results from the very low loading stress during nanoindentation, which is unable to lead to the catastrophic failure of alloys. At the onset of nanoindentation creep behavior, it has a relatively high strain rate between $10^{-3}$ and $10^{-4} \mathrm{~s}^{-1}$, which belongs to the transient-sate creep stage. When the holding time is extended, the strain rate decreases to $10^{-4} \mathrm{~s}^{-1}$ and enters the steady-state creep stage.

The creep stress exponent $(n)$ value is tightly linked to the creep mechanism. Usually, $n=1$ indicates the diffusion creep mechanism, $n=2$ indicates the grain boundary sliding mechanism, and $n=3-8$ indicates the dislocation creep mechanism [23]. For the Ti6Al4V alloy (sample A), the creep stress exponent is calculated to be $39.491 \pm 0.324$ for $10 \mathrm{mN}$, $7.213 \pm 0.017$ for $20 \mathrm{mN}, 4.201 \pm 0.012$ for $50 \mathrm{mN}$, and $2.556 \pm 0.009$ for $100 \mathrm{mN}$, respectively. Additionally, for the PBF-EB AM Ti6Al4V alloy (sample B), the creep stress exponent is calculated to be $11.89 \pm 0.02$ for $10 \mathrm{mN}, 2.666 \pm 0.004$ for $20 \mathrm{mN}, 1.572 \pm 0.003$ for $50 \mathrm{mN}$, and $1.842 \pm 0.004$ for $100 \mathrm{mN}$, respectively. The creep stress exponent of the PBF-EB AM Ti6Al4V alloy indicates that the creep behavior might be controlled by dislocation motion. The deformation induced by the indenter leads to a high density of dislocation and dislocation motion could effectively occur. Curiously, the calculated creep stress exponents decrease with increasing maximum loads $(10-100 \mathrm{mN})$, which is opposite to the results of $\mathrm{CoCrFeMnNi} \mathrm{HEAs} \mathrm{obtained} \mathrm{by} \mathrm{He} \mathrm{et} \mathrm{al.} \mathrm{[23].} \mathrm{Lee} \mathrm{et} \mathrm{al.} \mathrm{investigated} \mathrm{nanoindentation}$ 
creep behavior of $\mathrm{CoCrFeMnNi} \mathrm{high-entropy} \mathrm{alloys} \mathrm{and} \mathrm{obtained} \mathrm{creep} \mathrm{stress} \mathrm{exponent}$ $n=14.34$ for $P \max =10 \mathrm{mN}$ and $n=18.34$ for Pmax $=50 \mathrm{mN}$ [41].

\section{Conclusions}

In this study, the influences of scanning strategy during powder bed fusion electron beam additive manufacturing (PBF-EB AM) on microstructure, nano-mechanical properties, and creep behavior of Ti6Al4V alloy were compared. The results could contribute to understanding the creep behavior of Ti6Al4V alloy and are significant for PBF-EB AM of Ti6Al4V and other alloys. The conclusions can be summarized as follows:

Both PBF-EB AM Ti6Al4V alloys were composed of the predominant $\alpha$-Ti phase and barely $\beta$-Ti phase. Alloys with only the linear scanning strategy were composed of $96.9 \%$ $\alpha$-Ti and $2.7 \% \beta$-Ti phases, while alloys with linear and $90^{\circ}$ rotation scanning strategy were composed of $98.1 \% \alpha$-Ti and $1.9 \% \beta$-Ti phases. Additionally, the thickness of $\beta$ ribs in alloys with only the linear scanning strategy are a bit larger than those in the sample with the linear and $90^{\circ}$ rotation scanning strategy, but both have a value of lower than $1 \mu \mathrm{m}$.

The nanohardness of the PBF-EB AM Ti6Al4V alloy with linear scanning strategy is a bit higher than the value for alloys with linear and $90^{\circ}$ rotation scanning strategy. The nanoindentation hardness increased by a range of 4.11-6.31 GPa and 3.98-5.52 GPa with an improvement in the strain rate ranging from 0.001 to $1 \mathrm{~s}^{-1}$. The alloy with only the linear scanning strategy and $90^{\circ}$ rotation scanning strategy has a strain-rate sensitivity exponent $m=0.053 \pm 0.014$ and $m=0.047 \pm 0.009$, respectively.

The PBF-EB AM Ti6Al4V alloy with only the linear scanning strategy has better creep resistance properties than the alloy with a $90^{\circ}$ rotation scanning strategy. Increasing peak holding load (10-100 $\mathrm{mN}$ ) led to the dramatic increment of creep displacement (15-95 nm and $25-225 \mathrm{~nm}$ ) and the creep behavior was mainly dominated by dislocation motion during deformation induced by the indenter.

Author Contributions: Conceptualization, H.P. and W.F.; validation, H.P. and Y.Y.; formal analysis, H.P., W.F., C.D. and S.H.; investigation, H.P., X.W., B.L. and S.H.; data curation, H.P. and X.W.; writing—original draft preparation, H.P. and W.F.; writing—review and editing, C.D. and Y.Y.; visualization, H.P., W.F. and B.L.; project administration, W.F. and Y.Y.; funding acquisition, W.F. and Y.Y. All authors have read and agreed to the published version of the manuscript.

Funding: This research was funded by Key Area R\&D Program of Guangdong Province, China (No. 2018B090904004), Science and Technology Program of Guangzhou, China (No. 201907010010), Science and Technology Development Program provided by Guangdong Academy of Sciences, China (No. 2018GDASCX-0803), Guangzhou Economic and Technological Development Zone Program (No. 2019GH19).

Institutional Review Board Statement: Not applicable.

Informed Consent Statement: Not applicable.

Data Availability Statement: The data presented in this study are available on request from the corresponding author after obtaining permission of authorized person.

Conflicts of Interest: The authors declare that they have no known competing financial interests or personal relationships that could appear to influence the work reported in this paper.

\section{References}

1. Liu, G.; Zhang, X.F.; Chen, X.L.; He, Y.H.; Cheng, L.Z.; Huo, M.K.; Yin, J.N.; Hao, F.Q.; Chen, S.Y.; Wang, P.Y.; et al. Additive manufacturing of structural materials. Mater. Sci. Eng. 2021, 9, 100596. [CrossRef]

2. Cheng, B.; Price, S.; Lydon, J.; Cooper, K.; Chou, K. On Process Temperature in Powder-Bed Electron Beam Additive Manufacturing: Model Development and Validation. ASME J. Manuf. Sci. Eng. 2014, 136, 1-12. [CrossRef]

3. Bourell, D.; Kruth, J.P.; Leu, M.; Levy, G.; Rosen, D.; Beese, A.M.; Clare, A. Materials for additive manufacturing. Ann. Manuf. Technol. 2017, 66, 659-681. [CrossRef]

4. Zhao, Y.F.; Koizumi, Y.; Aoyagi, K.; Yamanaka, K.; Chiba, A. Isothermal $\gamma \rightarrow \varepsilon$ phase transformation behavior in a Co-Cr-Mo alloy depending on thermal history during electron beam powder-bed additive manufacturing. J. Mater. Sci. Technol. 2020, 50, 162-170. [CrossRef] 
5. Gao, B.; Peng, H.; Liang, Y.; Lin, J.; Chen, B. Electron beam melted TiC/high Nb-TiAl nanocomposite: Microstructure and mechanical property. Mater. Sci. Eng. A 2021, 811, 141059. [CrossRef]

6. Kuwabara, K.; Shiratori, H.; Fujieda, T.; Yamanaka, K.; Koizumi, Y.; Chiba, A. Mechanical and corrosion properties of AlCoCrFeNi high-entropy alloy fabricated with selective electron beam melting. Addit. Manuf. 2018, 23, 264-271. [CrossRef]

7. Wang, P.; Nai, M.L.S.; Sin, W.J.; Lu, S.L.; Zhang, B.C.; Bai, J.M.; Song, J.; Wei, J. Realizing a full volume component by in-situ welding during electron beam melting process. Addit. Manuf. 2018, 22, 375-380. [CrossRef]

8. Klimov, A.S.; Bakeev, I.Y.; Dvilis, E.S.; Oks, E.M.; Zenin, A.A. Electron beam sintering of ceramics for additive manufacturing. Vacuum 2019, 169, 108933. [CrossRef]

9. Leon, A.; Levy, G.K.; Ron, T.; Shirizly, A.; Aghion, E. The effect of hot isostatic pressure on the corrosion performance of Ti-6Al-4V produced by an electron-beam melting additive manufacturing process. Addit. Manuf. 2020, 33, 101039.

10. Popov, V.V.; Muller-Kamskii, G.; Katz-Demyanetz, A.; Kovalevsky, A.; Usov, S.; Trofimcow, D.; Dzhenzhera, G.; Koptyug, A. Additive manufacturing to veterinary practice: Recovery of bony defects after the osteosarcoma resection in canines. Biomed. Eng. Lett. 2019, 9, 97-108. [CrossRef] [PubMed]

11. Levy, G.K.; Kafri, A.; Ventura, Y.; Leon, A.; Vago, R.; Goldman, J.; Aghion, E. Surface stabilization treatment enhances initial cell viability and adhesion for biodegradable zinc alloys. Mater. Lett. 2019, 248, 130-133. [CrossRef]

12. Popov, V.V.; Muller-Kamskii, G.; Kovalevsky, A.; Dzhenzhera, G.; Strokin, E.; Kolomiets, A.; Ramon, J. Design and 3D-printing of titanium bone implants: Brief review of approach and clinical cases. Biomed. Eng. Lett. 2018, 8, 337-344. [CrossRef]

13. Rahmani, R.; Antonov, M.; Brojan, M. Lightweight 3D printed Ti6Al4V-AlSi10Mg hybrid composite for impact resistance and armor piercing shielding. J. Mater. Res. Technol. 2020, 9, 13842-13854. [CrossRef]

14. Rahmani, R.; Brojan, M.; Antonov, M.; Prashanth, K.G. Perspectives of metal-diamond composites additive manufacturing using SLM-SPS and other techniques for increased wear-impact resistance. Int. J. Refract. Met. Hard Mater. 2020, 88, 105192. [CrossRef]

15. Wu, Y.C.; Kuo, C.N.; Chung, Y.C.; Ng, C.H.; Huang, J.C. Effects of electropolishing on mechanical properties and bio-corrosion of Ti6Al4V fabricated by electron beam melting additive manufacturing. Materials 2019, 12, 1466. [CrossRef]

16. Tiferet, E.; Ganor, M.; Zolotaryov, D.; Garkun, A.; Hadjadj, A.; Chonin, M.; Ganor, Y.; Noiman, D.; Halevy, I.; Tevet, O.; et al. Mapping the tray of electron beam melting of Ti-6Al-4V: Properties and microstructure. Materials 2019, 12, 1470. [CrossRef] [PubMed]

17. Radlof, W.; Benz, C.; Heyer, H.; Sander, M. Monotonic and fatigue behavior of EBM manufactured Ti-6Al-4V solid samples: Experimental, analytical and numerical investigations. Materials 2020, 13, 4642. [CrossRef]

18. Neikter, M.; Colliander, M.; Schwerz, C.d.A.; Hansson, T.; Akerfeldt, P.; Pederson, R.; Antti, M.L. Fatigue crack growth of electron beam melted Ti-6Al-4V in high-pressure hydrogen. Materials 2020, 13, 1287. [CrossRef]

19. Tan, X.P.; Chandra, S.; Kok, Y.; Tor, S.B.; Seet, G.; Loh, N.H.; Liu, E. Revealing competitive columnar grain growth behavior and periodic microstructural banding in additively manufactured Ti-6Al-4V parts by selective electron beam melting. Materialia 2019, 7, 100365. [CrossRef]

20. Wei, C.B.; Ma, X.L.; Yang, X.J.; Zhou, M.; Wang, C.M.; Zheng, Y.F.; Zhang, W.P.; Li, Z.J. Microstructural and property evolution of Ti6Al4V powders with the number of usage in additive manufacturing by electron beam melting. Mater. Lett. 2018, 221, 111-114. [CrossRef]

21. Oliveira, V.M.C.A.; Silva, M.C.L.; Pinto, C.G.; Suzuki, P.A.; Machado, J.P.B.; Chad, V.M.; Barboza, M.J.R. Short-term creep properties of Ti-6Al-4V alloy subjected to surface plasma carburizing process. J. Mater. Res. Technol. 2015, 4, 359-366. [CrossRef]

22. Kim, Y.K.; Youn, S.J.; Kim, S.W.; Hong, J.; Lee, K.A. High-temperature creep behavior of gamma Ti-48Al-2Cr-2Nb alloy additively manufactured by electron beam melting. Mater. Sci. Eng. A 2019, 763, 138138. [CrossRef]

23. Yavari, P.; Langdon, T.G. An examination of the breakdown in creep by viscous glide in solid solution alloys at high stress levels. Acta Metall. 1982, 30, 2181-2196. [CrossRef]

24. Gouldstone, A.; Koh, H.J.; Zeng, K.Y.; Giannakopoulos, A.E.; Suresh, S. Discrete and continuous deformation during nanoindentation of thin films. Acta Mater. 2000, 48, 2277-2295. [CrossRef]

25. Xu, Z.L.; Zhang, H.; Li, W.H.; Mao, A.Q.; Wang, L.; Song, G.S.; He, Y.Z. Microstructure and nanoindentation creep behavior of CoCrFeMnNi high-entropy alloy fabricated by selective laser melting. Addit. Manuf. 2019, 28, 766-771. [CrossRef]

26. Sun, S.; Gao, P.; Sun, G.X.; Cai, Z.; Hu, J.J.; Han, S.; Lian, J.S.; Liao, X.Z. Nanostructuring as a route to achieve ultra-strong highand medium-entropy alloys with high creep resistance. J. Alloys Compd. 2020, 830, 154656. [CrossRef]

27. Jun, T.S.; Armstrong, D.E.J.; Britton, T.B. A nanoindentation investigation of local strain rate sensitivity in dual-phase Ti alloys. J. Alloys Compd. 2016, 672, 282-291. [CrossRef]

28. Li, H.; Ngan, A.H.W. Size effects of nanoindentation creep. J. Mater. Res. 2004, 19, 513-522. [CrossRef]

29. Wang, C.L.; Lai, Y.H.; Huang, J.C.; Nieh, T.G. Creep of nanocrystalline nickel: A direct comparison between uniaxial and nanoindentation creep. Scr. Mater. 2010, 62, 175-178. [CrossRef]

30. Goodall, R.; Clyne, T.W. A critical appraisal of the extraction of creep parameters from nanoindentation data obtained at room temperature. Acta Mater. 2006, 54, 5489-5499. [CrossRef]

31. Poisl, W.H.; Oliver, W.C.; Fabes, B.D. The relationship between indentation and uniaxial creep in amorphous selenium. J. Mater. Res. 1995, 10, 2024-2032. [CrossRef]

32. Choi, I.C.; Yoo, B.G.; Kim, Y.J.; Jang, J.I. Indentation creep revisited. J. Mater. Res. 2011, 27, 3-11. [CrossRef] 
33. Shen, L.; Cheong, W.C.D.; Foo, Y.L.; Chen, Z. Nanoindentation creep of tin and aluminium: A comparative study between constant load and constant strain rate methods. Mater. Sci. Eng. A 2012, 532, 505-510. [CrossRef]

34. Song, J.; Wu, W.H.; Zhang, L.; He, B.B.; Lu, L.; Ni, X.Q.; Long, Q.L.; Zhu, G.L. Role of scanning strategy on residual stress distribution in Ti-6Al-4V alloy prepared by selective laser melting. Optik 2018, 170, 342-352. [CrossRef]

35. Wang, X.; Lv, F.; Shen, L.D.; Liang, H.X.; Xie, D.Q.; Tian, Z.J. Influence of island scanning strategy on microstructures and mechanical properties of direct laser-deposited Ti-6Al-4V structures. Acta Metall. Sin. 2018, 32, 1173-1180. [CrossRef]

36. Peng, H.L.; Hu, L.; Li, L.J.; Zhang, L.Y.; Zhang, X.L. Evolution of the microstructure and mechanical properties of powder metallurgical high-speed steel S390 after heat treatment. J. Alloys Compd. 2018, 740, 766-773. [CrossRef]

37. Kenel, C.; Grolimund, D.; Li, X.; Panepucci, E.; Samson, V.A.; Sanchez, D.F.; Marone, F.; Leinenbach, C. In situ investigation of phase transformations in Ti-6Al-4V under additive manufacturing conditions combining laser melting and high-speed micro-X-ray diffraction. Sci. Rep. 2017, 7, 16358. [CrossRef] [PubMed]

38. Zhao, X.L.; Li, S.J.; Zhang, M.; Liu, Y.D.; Sercombe, T.B.; Wang, S.G.; Hao, Y.L.; Yang, R.; Murr, L.E. Comparison of the microstructures and mechanical properties of Ti-6Al-4V fabricated by selective laser melting and electron beam melting. Mater. Des. 2016, 95, 21-31. [CrossRef]

39. Ma, R.X.; Liu, Z.Q.; Wang, W.B.; Xu, G.J.; Wang, W. Microstructures and mechanical properties of Ti6Al4V-Ti48Al2Cr2Nb alloys fabricated by laser melting deposition of powder mixtures. Mater. Charact. 2020, 164, 110321. [CrossRef]

40. Chen, G.L.; Xu, X.J.; Teng, Z.K.; Wang, Y.L.; Lin, J.P. Microsegregation in high Nb containing TiAl alloy ingots beyond laboratory scale. Intermetallics 2007, 15, 625-631. [CrossRef]

41. Takashima, T.; Koizumi, Y.; Li, Y.P.; Yamanaka, K.; Saito, T.; Chiba, A. Effect of Building Position on Phase Distribution in Co-Cr-Mo Alloy Additive Manufactured by Electron-Beam Melting. Mater. Trans. 2016, 57, 2041-2047. [CrossRef]

42. Peng, H.L.; Hu, L.; Li, L.J.; Gao, J.X.; Zhang, Q. On the correlation between $\mathrm{L1}_{2}$ nanoparticles and mechanical properties of $(\mathrm{NiCo})_{52+2 \mathrm{x}}(\mathrm{AlTi})_{4+2 \mathrm{x}} \mathrm{Fe}_{29-4 \mathrm{x}} \mathrm{Cr}_{15}(\mathrm{x}=0-4)$ high-entropy alloys. J. Alloys Compd. 2020, 817, 152750. [CrossRef]

43. VNguyen, L.; Kim, E.A.; Yun, J.; Choe, J.; Yang, D.Y.; Lee, H.S.; Lee, C.W.; Yu, J.H. Nano-mechanical Behavior of H13 Tool Steel Fabricated by a Selective Laser Melting Method. Metall. Mater. Trans. A 2019, 50, 523-528.

44. Duan, Z.; Pei, W.; Gong, X.; Chen, H. Superplasticity of Annealed H13 Steel. Materials 2017, 10, 870. [CrossRef] [PubMed]

45. Surand, L.B.; Ruau, J.; Viguier, B. Creep behavior of Ti-6Al-4V from $450{ }^{\circ} \mathrm{C}$ to $600{ }^{\circ}$ C, U.P.B. Sci. Bull. $2014,76,185-196$.

46. Barboza, M.J.R.; Perez, E.A.C.; Medeiros, M.M.; Reis, D.A.P.; Nono, M.C.A.; Neto, F.P.; Silva, C.R.M. Creep behavior of Ti-6Al-4V and a comparison with titanium matrix composites. Mater. Sci. Eng. A 2006, 428, 319-326. [CrossRef] 